\title{
Investigation of Intake and Exhaust Manifolds Parameters of a Turbocharged Diesel Engine Based on Steady-State Simulation
}

\author{
Brahim MENACER*, Boussad AIT SLIMANE**, Mostefa BOUCHETARA*** \\ Aeronautics and Systems Propelling Laboratory, Department of Mechanical Engineering, University of Sciences and the \\ Technology of Oran. address: BP 1505 El -Mnaouer, USTO 31000 Oran (Algeria) Oran 31000 Algeria, \\ E-mail:*acer.msn@hotmail.fr, **azizmaraval@hotmail.com,***mbouchetara@hotmail.com

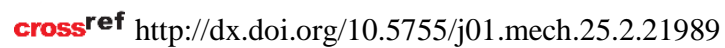

\section{Introduction}

The rapid development of computer technology has encouraged the use of complex simulation techniques to quantify the effect of the fundamental processes in engine. The advances achieved by current automotive engines would have been impossible without the simulation models providing these insights. The models have evolved from the ideal cycle calculations in the 1950 s to simple component matching models in the 1960s, full thermodynamic models during the late 1970s and multi-zone and multidimensional combustion models in the 1980s and early 1990s. The highresolution multidimensional models, such as KIVA II 3-D [1], are often used for specific problem areas in design, where details of fluid transport processes or those involving subtle geometry changes dominate. These models are capable of simulating detailed airflow, spray and combustion events in local geometries. The developed models in order of increasing complexity are the quasi-steady, filling and emptying and the wave dynamics models. The quasi-steady simulations are dependent on empirical knowledge and do not allow for mass accumulation between components. The filling and emptying models are based on solving the mass and energy conservation equations of a thermodynamic control volume. This method represents the unsteady flow phenomena more realistically as it models the time varying properties of flow and allows for mass accumulation between the engine components. The wave dynamics method analyses even more detail as it tracks the pressure wave and temperature discontinuity along manifolds. Such models are more accurate in representing long pipes where pressure wave effects are prevalent. A detailed manifold design requires the use of a wave action model. The objective of this work is to conduct a comparative study of simulation results of the intake and the exhaust manifolds flow parameters of a six-cylinder direct injection turbocharged compression ignition engine based on steady-state simulation for different mass fuel injected and engine speed. The results obtained with the elaborate calculation code in FORTRAN language and those with the GT-Power software.

\section{Models approach}

The turbocharged diesel engine is defined as a collection of interacting elements that function together to produce a desired power output for a particular purpose. The thermodynamic properties of gases in an element of the engine will vary as it exchanges energy (in the form of work or heat) or mass with another element. The engine approach to modelling emphasizes the connections between the various parts that constitute the whole. It is concerned with the overall completeness of the model. The overall structure of the engine model as illustrated in Fig. 1; shows the elements of the engine, the corresponding governing laws: equations and some possible sub-models applicable. The fundamental element included in an engine is the cylinder, usually described by the filling and emptying (zero-dimensional) model. The inlet and exhaust manifolds can be represented by either the filling and emptying or a gas dynamics model. Junctions representing valves and orifices are described by quasi-steady compressible flow models. The turbocharger model uses tabulated performance maps which are interpolated during the simulation to evaluate the mass flow rate and isentropic efficiency. We have combined these elements to study the evaluation of gas performance parameters of the intake and the exhaust manifold.

\section{Diesel engine model}

\subsection{Engine structure and model hypothesis}

The turbocharged direct injection diesel engine is studied in this work. A turbocharger is fitted to the engine to improve its low power density; it consists of a compressor powered by a fixed geometry turbine. Engine parts (cylinders, intake and exhaust manifolds) are modelled as separate thermodynamic systems containing gases at uniform state. With respect to the filling and emptying method; mass, temperature and pressure of gas are calculated using first law and mass conservation. The main simplifying assumptions for this model are:

$\checkmark \quad$ Ideal gases with constant specific heats;

$\checkmark$ Effects of heat transfer through intake and exhaust manifolds are neglected;

$\checkmark$ The engine cylinder wall temperature $T_{\text {wall }}$ is supposed to be steady and homogenous;

$\checkmark$ Compressor inlet and turbine outlet temperatures and pressures are assumed to be equal to ambient pressure $p_{a}$ and temperature $T_{a}$.

\subsection{Turbocharger dynamics model}

The rotational speed of the turbocharger assembly $\omega_{t c}$ can be derived from Newton's law:

$$
\frac{d \omega_{t c}}{d t}=\frac{P_{t}-P_{c}}{J_{t c} \omega_{t c}},
$$

where: $J_{t c}$ is turbocharger moment of inertia, $P_{t}$ and $P_{c}$ are turbine and compressor power. Here, the bearing frictions are neglected. 


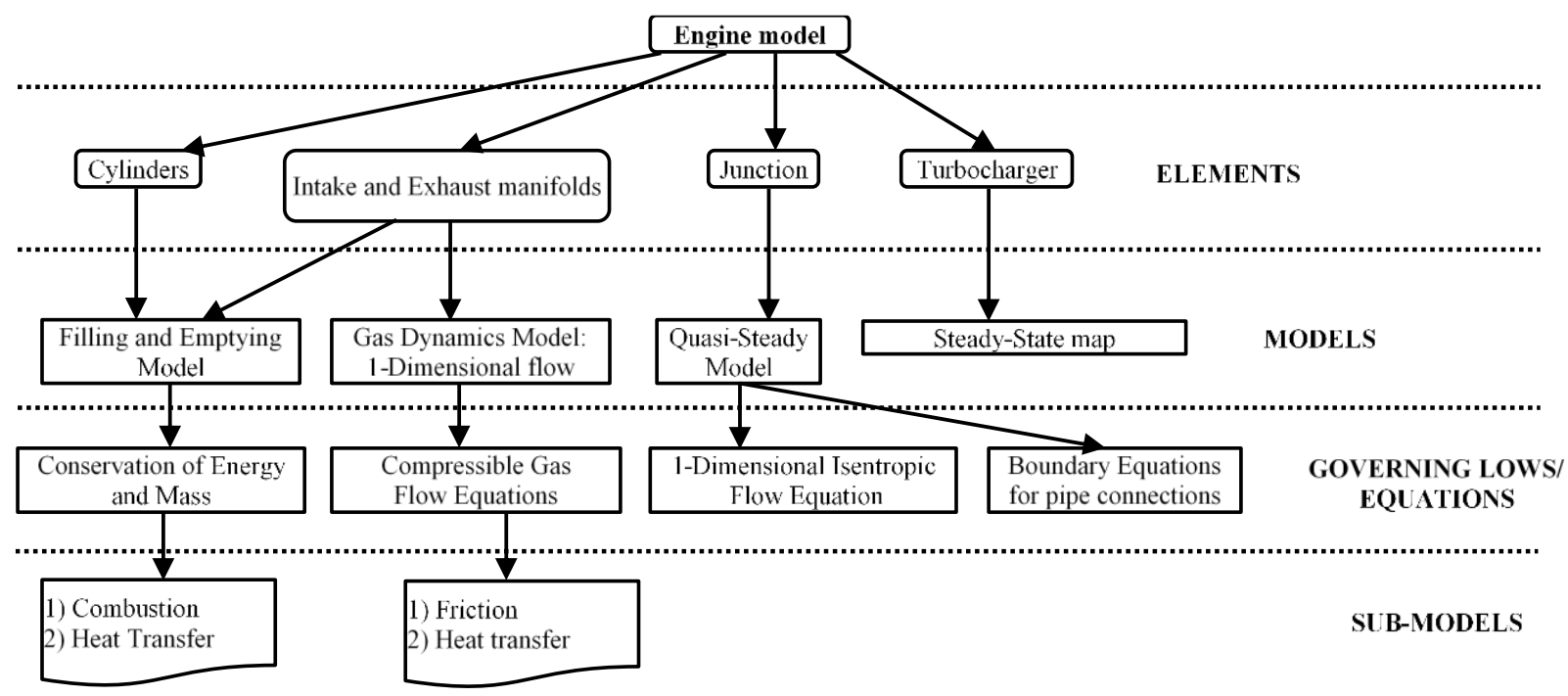

Fig. 1 Overall structure of an engine model [2]

\subsection{Compressor model}

Assuming the heat losses are neglected, the compressor power $P_{c}$ is derived from first law of thermodynamics [3]:

$$
\begin{aligned}
& P_{c}=\dot{m}_{c} c_{p} \frac{1}{\eta_{c}} T_{a}\left[\pi_{c}^{\frac{\gamma-1}{\gamma}}-1\right] \text { with } \pi_{c}=\left(\frac{p_{1}}{p_{a}}\right), \\
& \left\{\begin{array}{l}
\dot{m_{c}}=f_{c, \dot{m}}\left(\omega_{t c}, \pi_{c}\right) \\
\eta_{c}=f_{c, \eta}\left(\omega_{t c}, \pi_{c}\right)
\end{array}\right.
\end{aligned}
$$

The compressor power is related to the mass flow rate through the compressor $m_{c}$, the isentropic efficiency $\eta_{c}$ and the inlet and outlet temperatures and pressures. Efficiency and mass flow are usually mapped according to pressure ratio $\pi_{c}$ and turbocharger speed $\omega_{t c}$. Temperature of the air downstream to the compressor is given by:

$$
T_{c}=T_{a}\left[1+\frac{1}{\eta_{c}}\left(\pi_{c}^{\frac{\gamma-1}{\gamma}}-1\right)\right]
$$

\subsection{Turbine model}

Turbine power is derived in the similar way as equation (2) for the compressor:

$$
P_{t}=\dot{m}_{t} c_{p} \eta_{t} T_{2}\left[1-\pi_{t}^{\frac{1-\gamma}{\gamma}}\right] \text { with } \pi_{t}=\left(\frac{p_{2}}{p_{a}}\right)
$$

However, mass flow $\dot{m}_{t}$ and efficiency $\eta_{t}$ are not mapped. First, the turbine mass flow is modeled in the same way as a flow across valve or throttle [4-5]:

$$
\dot{m}_{t}=A_{t} c_{t} \varphi\left(p_{a}, p_{2}, T_{a}, T_{2}\right),
$$

where: $A_{t}$ is turbine area.

Second, the convectional approach to parameterize the turbine efficiency $\eta_{t}$ is based on the blade speed ratio $c_{u}$ instead of turbocharger speed:

$$
\begin{aligned}
& \eta_{t}\left(c_{u}\right)=\eta_{t, \max }\left[2 \frac{c_{u}}{c_{u, o p t}}-\left(\frac{c_{u}}{c_{u, o p t}}\right)^{2}\right], \\
& \text { with; } c_{u}=r_{t} \omega_{t c}\left(2 c_{p} T_{2}\left(1-\pi_{t}^{\left(\frac{\gamma-1}{\gamma}\right)}\right)\right)^{-0.5} .
\end{aligned}
$$

Parameters $c_{u, o p t}$ and $\eta_{t, \text { max }}$ may be taken as constant values [5].

\subsection{Inlet and exhaust manifolds model}

Since heat transfer on manifold wall is neglected, the equations for mass and pressure inside the intake manifold are written as follows [6]:

$$
\begin{aligned}
& \frac{d m_{1}}{d t}=\dot{m}_{c}+\sum_{j=1}^{n_{c y l}} \dot{m}_{c y l_{j} / 1}-\sum_{j=1}^{n_{c y l}} \cdot \dot{m}_{1 / c y l_{j}}, \\
& \frac{d p_{1}}{d t}=\frac{\gamma R}{V_{1}}\left[T_{c} \dot{m}_{c}+\sum_{j=1}^{n_{c y l}} T_{c y l_{j}} \dot{m}_{c y l_{j} / 1}-T_{1} \sum_{j=1}^{n_{c y l}} \cdot \dot{m}_{1 / c y l_{j}}\right] .
\end{aligned}
$$

State equations for the exhaust manifold are derived in the same way and give:

$$
\begin{aligned}
& \frac{d m_{2}}{d t}=\sum_{j=1}^{n_{c y l}} \dot{m}_{c y l_{j} / 2}-\sum_{j=1}^{n_{c y l}} \dot{m}_{2 / c y l_{j}}-\dot{m}_{t}, \\
& \frac{d p_{2}}{d t}=\frac{\gamma R}{V_{2}}\left[\sum_{j=1}^{n_{c y l}} T_{c y l_{j}} \dot{m}_{c y l_{j} / 2}-T_{2} \sum_{j=1}^{n_{c y l}} \dot{m}_{2 / c y l_{j}}-T_{t} \dot{m}_{t}\right] .
\end{aligned}
$$

The manifold temperatures $T_{1}$ and $T_{2}$ are calculated from the ideal gas law, $T_{x}=V_{x} p_{x} /\left(R m_{x}\right)$. 
3.6. Intake and exhaust valves model

Flows across the intake and the exhaust valves are modelled by the standard orifice flow Eq. [6]:

$$
\left\{\begin{array}{l}
m_{i v_{j}}=A_{i v}\left[l_{i v}\left(\theta_{j}\right)\right] \varphi\left(p_{c y l_{j}}, p_{1}, T_{c y l_{j}}, T_{1}\right) \\
m_{e v_{j}}=A_{e v}\left[l_{e v}\left(\theta_{j}\right)\right] \varphi\left(p_{2}, p_{c y l_{j}}, T_{2}, T_{c y l_{j}}\right)
\end{array} .\right.
$$

The effective orifice areas $A_{i v}$ and $A_{e v}$ (including the discharge coefficient) depend on the intake and the exhaust valve lift maps $l_{i v}$ and $l_{e v}$ provided by the manufacturer. Since subscripts $u$ and $d$ refer to upstream and downstream variables, thus, function $\varphi$ may be written as follows, [7]:

$$
\varphi=\left\{\begin{array}{lll}
\frac{p_{u}}{\sqrt{R T_{u}}} \varphi^{+}\left(\frac{p_{d}}{p_{u}}\right) & \text { if } & p_{d} \leq p_{u} \\
\frac{p_{d}}{\sqrt{R T_{d}}} \varphi^{+}\left(\frac{p_{u}}{p_{d}}\right) & \text { if } & p_{u} \succ p_{d}
\end{array} .\right.
$$

The flow can be in the forward or reverse direction (backflow). Moreover, we must distinguish subsonic and supersonic flows. The flow is assumed to be subsonic when the pressure ratio is lower than the critical ratio $c_{r}$ and supersonic otherwise. Thus, function $\varphi^{+}(x)$ takes two different forms, [7]:

$$
\varphi^{+}(x)=\left\{\begin{array}{ccc}
\gamma^{\frac{1}{2}}\left(\frac{2 \gamma}{\gamma+1}\right)^{\frac{\gamma+1}{2(\gamma-1)}} & \text { if } & x \leq c_{r}, \\
x^{\frac{1}{\gamma}} \sqrt{\frac{2 \gamma}{\gamma-1}\left(1-x^{\frac{\gamma-1}{\gamma}}\right)} & \text { if } & x \succ c_{r}
\end{array},\right.
$$

with the critical ratio: $c_{r}=\left(\frac{2}{\gamma+1}\right)^{\frac{\gamma}{\gamma-1}}$.

For the proposed engine model, we assume that backflow may occur through the intake and exhaust valves. As a result, the valve flows are separated in two distinct terms, one representing the direct flow and the other the backflow, thus, equation (14) can be rewritten as:

$$
\left\{\begin{array}{l}
m_{i v_{j}}=\dot{m}_{1 / c y l_{j}}-\dot{m}_{c y l_{j} / 1} \\
m_{e v_{j}}=\dot{m}_{2 / c y l_{j}}-\dot{m}_{c y l_{j} / 2}
\end{array} .\right.
$$

The total temperature $T_{t}$ at any point in the flow at the intake or the exhaust valves is given by Eqs. (17) and (18):

$$
\begin{aligned}
& C_{p} T_{t \text { int }}=C_{p} T_{\text {int }}+\frac{v_{\text {int }}^{2}}{2}, \\
& C_{p} T_{t e x h}=C_{p} T_{e x h}+\frac{v_{e x h}{ }^{2}}{2} .
\end{aligned}
$$

The mach number $M_{a}$ at intake or exhaust valves is determined using equation (19) and (20):

$$
\begin{aligned}
& M_{\text {aint }}=\frac{v_{\mathrm{int}}}{c_{\mathrm{int}}}=\frac{v_{\mathrm{int}}}{\sqrt{\gamma R T_{\mathrm{int}}}}, \\
& M_{\text {aexh }}=\frac{v_{e x h}}{c_{e x h}}=\frac{v_{e x h}}{\sqrt{\gamma R T_{e x h}}},
\end{aligned}
$$

where: $c_{\text {int }, e x h}, v_{\text {int }, e x h}$ : velocity of sound and gas velocity at intake and exhaust valves.

The relationship between the total and static temperature in the diesel engine intake and exhaust valves are giving by Eqs. (21) and (22):

$$
\begin{aligned}
& \frac{T_{t \text { int }}}{T_{\text {int }}}=1+(\gamma-1) \frac{M_{a \mathrm{int}}^{2}}{2}, \\
& \frac{T_{t e x h}}{T_{e x h}}=1+(\gamma-1) \frac{M_{a e x h}^{2}}{2} .
\end{aligned}
$$

\subsection{Cylinder model}

\subsubsection{Zero dimensional model}

The cylinder is the fundamental part of the system. In the basic modeling approach developed by Borman [8], energy balance gives the rate of change of cylinder gas temperature $\dot{T}_{c y l}$. This approach leads to an ordinary differential equation for $T_{c y l}$ including some partial derivative terms evaluated from the gas property relationship [9]. In order to simplify the mathematical formulation and to reduce the computing time, the number of derivative operations is limited. Thus, pressure inside the cylinder $j, p_{c y l}$, is obtained by differentiating the first law of thermodynamics for an ideal gas with constant specific heat and the mass $m_{c y l_{j}}$ is derived from the mass continuity equation:

$$
\left\{\begin{array}{l}
\frac{d m_{c y l_{j}}}{d t}=\dot{m}_{f}+\dot{m}_{1 / c y l_{j}}+\dot{m}_{2 / c y l_{j}}-\dot{m}_{c y l_{j} / 1}-\dot{m}_{c y l_{j} / 2}, \\
\frac{d p_{c y l_{j}}}{d t}=\frac{\gamma}{V_{c y l_{j}}}\left[R T_{1} \dot{m}_{1 / c y l_{j}}-R T_{c y l_{j}}\left(\dot{m}_{c y l_{j} / 1}+\dot{m}_{c y l_{j} / 2}\right)\right]+ \\
+\frac{\gamma}{V_{c y l_{j}}}\left(R T_{2} \dot{m}_{2 / c y l_{j}}-p_{c y l_{j}} \dot{V}_{c y l_{j}}\right)+\frac{\gamma-1}{V_{c y l_{j}}}\left[\dot{m}_{b f_{j}} Q_{L H V}-\dot{Q}_{h t_{j}}\right],
\end{array}\right.
$$


where; $\dot{m}_{b f_{j}} Q_{L H V}:$ rate of heat release, $\dot{Q}_{h t_{j}}$ : rate of heat transfer to the engine block. After each integration step, the cylinder gas temperature is deduced from the ideal gas law.

\subsubsection{Fuel mass burning rate model}

The combustion process in direct injection diesel engine involves two distinct stages. The first stage is a quick combustion process named premixed which occurs in few crank angle degrees. The second stage called diffusion ends the combustion. Diesel combustion is modelled by Watson and Marzouk [10]. The amount of heat release $\dot{Q}_{\text {comb }}$ is assumed proportional to the burned fuel mass:

$$
\frac{d Q_{c o m b}}{d t}=\frac{d m_{f b}}{d t} h_{f o r} .
$$

The fuel burning rate according to injected mass per cycle, the combustion duration and the mass fuel burning rate may be written as, for more information see [11]:

$$
\frac{d m_{f b}}{d t}=\frac{d m_{f b}^{*}}{d t} \frac{m_{f}}{\Delta t_{c o m b}} .
$$

\subsubsection{Heat transfer model}

Typically, the 20 to $35 \%$ of the fuel energy is passed on by the heat transfer to the engine coolant [12], [13]. The primary heat transfer mechanism from the cylinder gases to the surrounding areas is the convection through cylinder wall. The heat loss to the wall is generally given by:

$$
\frac{d Q_{h t}}{d t}=A_{c y l^{h} t}\left(T_{c y l}-T_{w a l l}\right)
$$

where: $A_{c y l}$ is corresponds to the convention area derived from the cylinder geometry, $T_{\text {wall }}$ is average temperature of surrounding area. The convection heat transfer coefficient $h_{t}$ can be estimated by the empirical approach of Hohenberg [14]:

$$
h_{t}(t)=130 \times p_{c y l}^{0.8} V_{c y l}^{-0.06} T_{c y l}^{-0.4}\left(v_{p i s}^{-}+1.4\right)^{0.8}
$$

\section{Simulation and validation}

All the equations of the model were coded in FORTRAN language. After compilation, the program is executed. The evolution of the state variables of the model is obtained by numerical integration of differential equations described in the previous sections [15]. There are several methods for the integration of differential systems (RungeKutta, Adams, etc.). In this work, the choice of the integration method is focused on the fixed step algorithm of RungeKutta (ode5 function) [16], [17]. For the closed cycle period, Watson recommended the following engine calculation crank angle steps: $10^{\circ} \mathrm{CA}$ before ignition, $1^{\circ} \mathrm{CA}$ at fuel injection timing, $2^{\circ} \mathrm{CA}$ between ignition and combustion end, and finally $10^{\circ} \mathrm{CA}$ for expansion, see Fig. 2 .

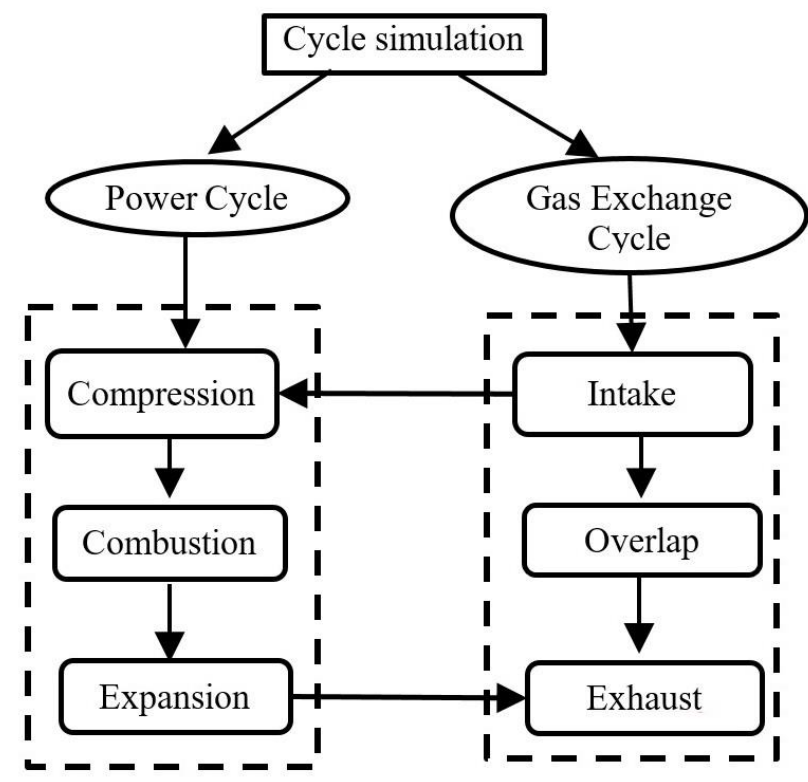

Fig. 2 Sequence of processes followed by cycle-related engine simulations

\subsection{How GT-Power generates a solution}

GT-Power is based on one-dimensional gas dynamics which account for fluid flows and heat transfer. Each component in a GT-Power model is discretized in many smaller components. These subcomponents have very small volumes and the fluid's scalar properties in these volumes are assumed to be constant. The scalar properties of a fluid include pressure, temperature, density and internal energy. Each volume also has vector properties that can be transferred across its boundaries. These properties include mass flux and fluid velocity. GT-Power determines the change in the scalar properties by solving simultaneous one-dimensional equation. Fig. 3 shows the model of a turbocharged diesel engine with 6 cylinders and intercooler made with GT-Power. In the intake manifold, the variation of the mass depends on the compressor mass flow and the flow through of valves when they are open. In the modeling view, the line of exhaust manifold of the engine is composed in three volumes; the cylinders are grouped by three and emerge on two independent manifold, component two thermodynamic systems opened of identical volumes, and a third volume smaller assures the junction with the wheel of the turbine. In the turbocharger; the compressor is powered by the turbine which is driven by exhaust gas. In the heat exchanger, it comes to solve a system of differential equations supplementary identical to the manifold. For the validation, we compared the model output (FORTRAN program) with their analogues obtained through an industry code of calculations; GT-Power.The main parameters of the chosen direct-injection diesel engine [10] are: Bore: 120.0 [mm], Stroke: 175.0 [mm], Connecting rod length: 300.0 [mm], Inlet valve diameter: 60 [mm], Exhaust valve diameter: 38 [mm], Inlet Valve Open: 314 [ ${ }^{\circ} \mathrm{CA}$ ], Inlet Valve Close: -118 $\left[{ }^{\circ} \mathrm{CA}\right]$, Exhaust Valve Open: $100\left[{ }^{\circ} \mathrm{CA}\right]$, Exhaust Valve Close: $400\left[{ }^{\circ} \mathrm{CA}\right]$. 


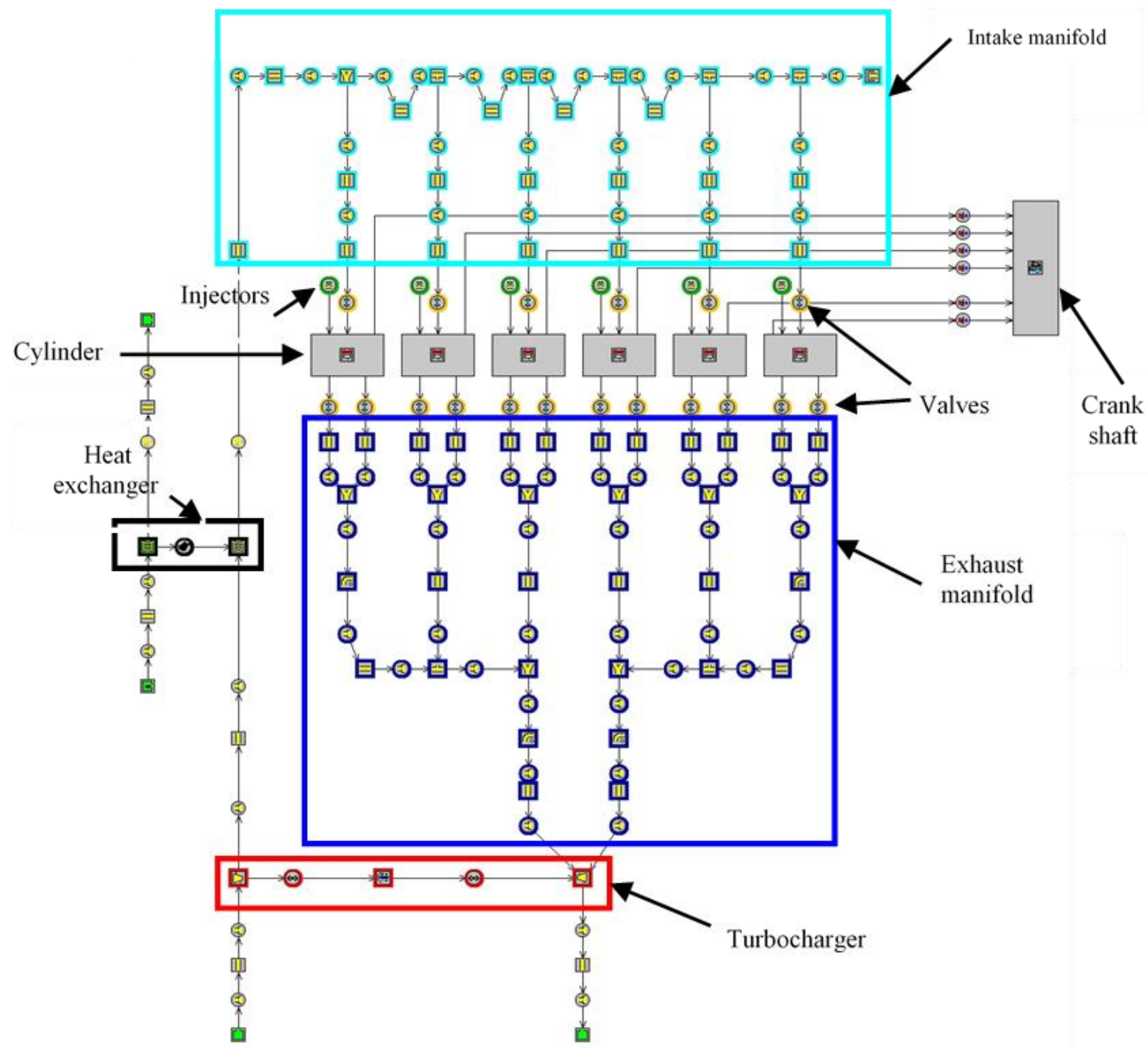

Fig. 3 Six-cylinders turbocharged direct injection diesel engine model using the GT-Power software [4]

\section{Results and interpretation}

\subsection{Intake and exhaust manifolds parameters}

Figs. 4, 5 and 6 represents the evolution of pressure, temperature and mass flow rate in the intake manifolds versus engine speed and load. For a given load, the three parameters increase linearly with the engine speed. There is

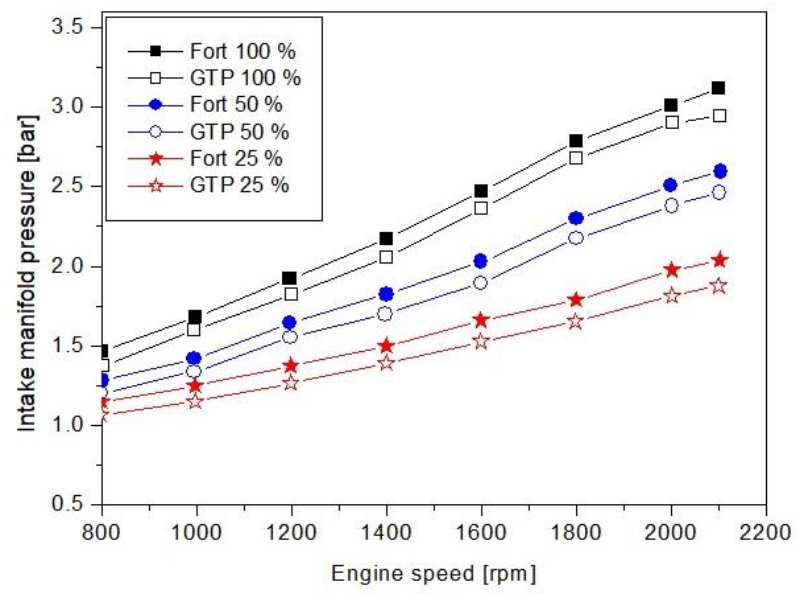

Fig. 4 Intake manifold pressure good concordance between the elaborate model in FORTRAN and the GT-Power software.

The evolution of pressure, temperature and mass flow rate in the exhaust manifolds versus engine speed and load are showed in Figs. 7, 8 and 9. For a given load, the pressure and mass flow rate increases, but the temperature decreases linearly with engine speed. There is also a good agreement between the results for the two software; FORTRN and GT-Power.

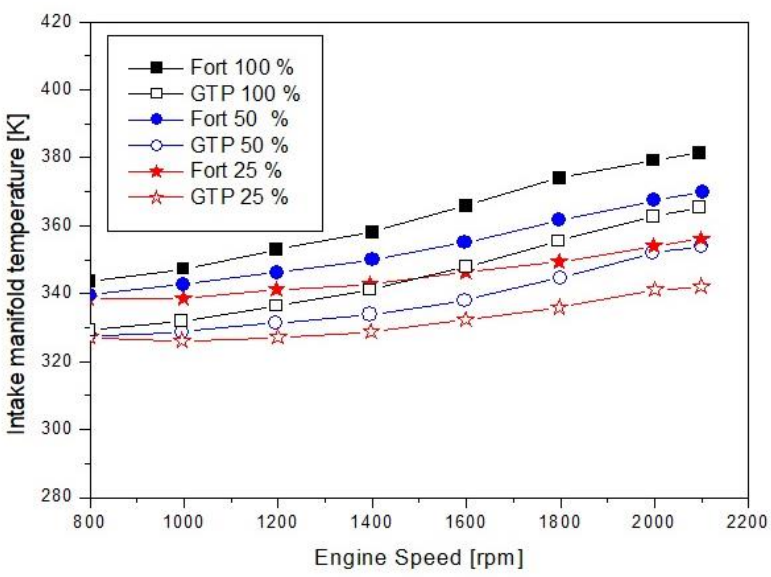

Fig. 5 Intake manifold temperature 


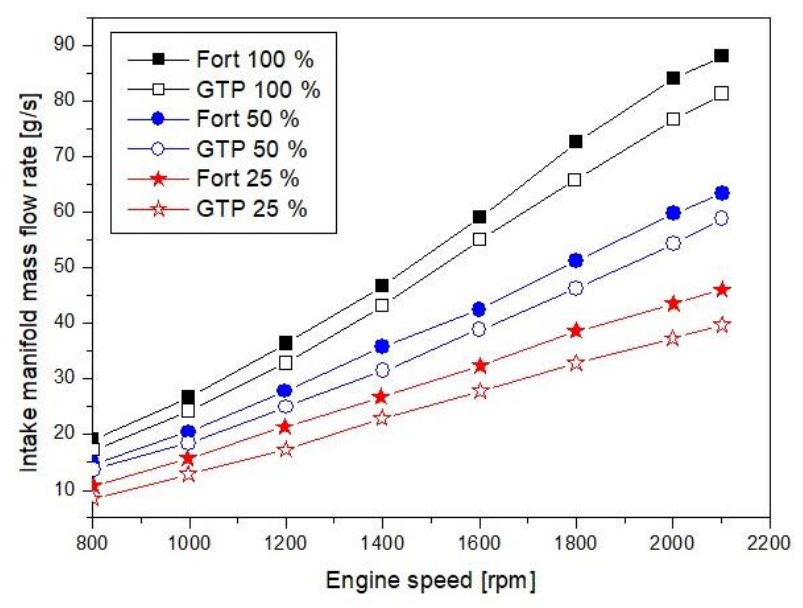

Fig. 6 Intake manifold mass flow rate

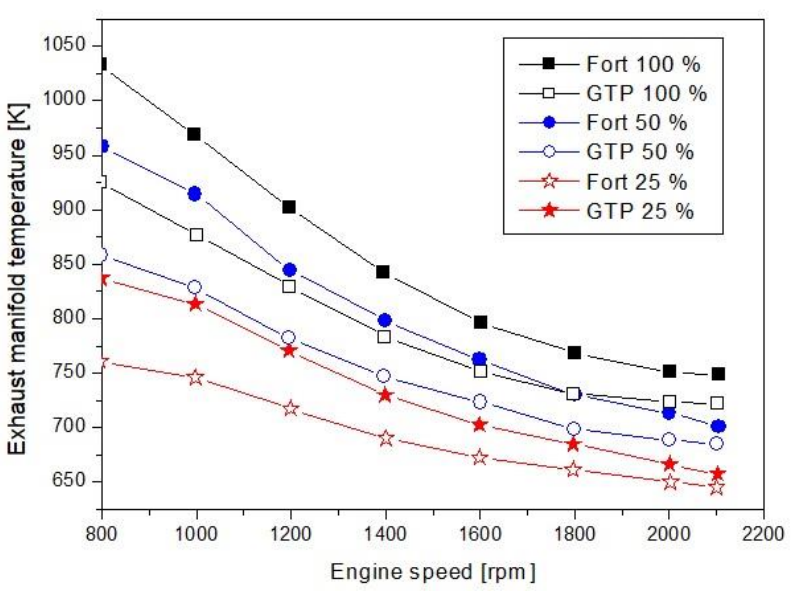

Fig. 8 Exhaust manifold temperature

\subsection{Intake and exhaust valves parameters}

Figs. 10 and 11 shows the variation of the pressure at the inlet and exhaust valves with respect to crank angle, for different engine speeds. It is observed that the graphs exhibit almost similar characteristics in different magnitudes as engine speed changes. This clearly illustratesthe unsteady nature of the flow in the intake and exhaust valves of the engine. It is also observed that there is a sudden increase in the pressure at the first just after IVO; this is because the pressure inside the cylinder is slightly higher than the intake

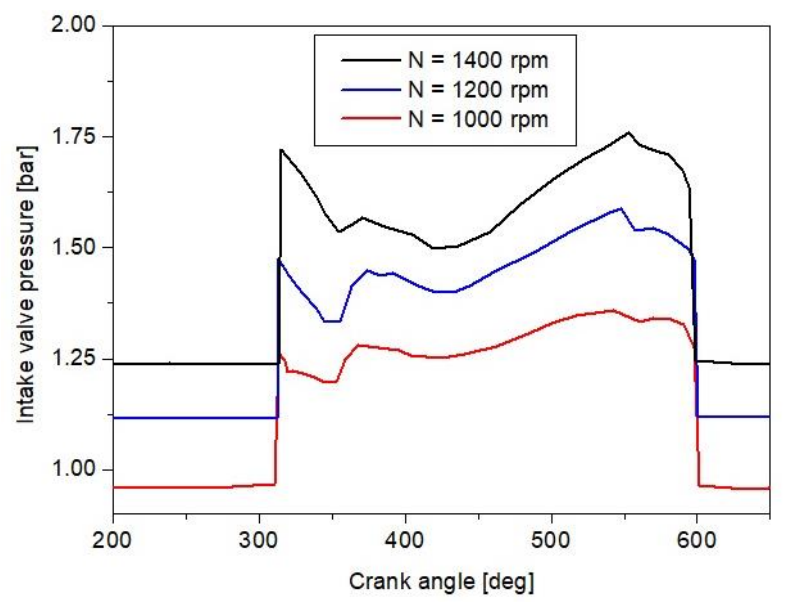

Fig. 10 Pressure variations in the intake valve during gas exchange period

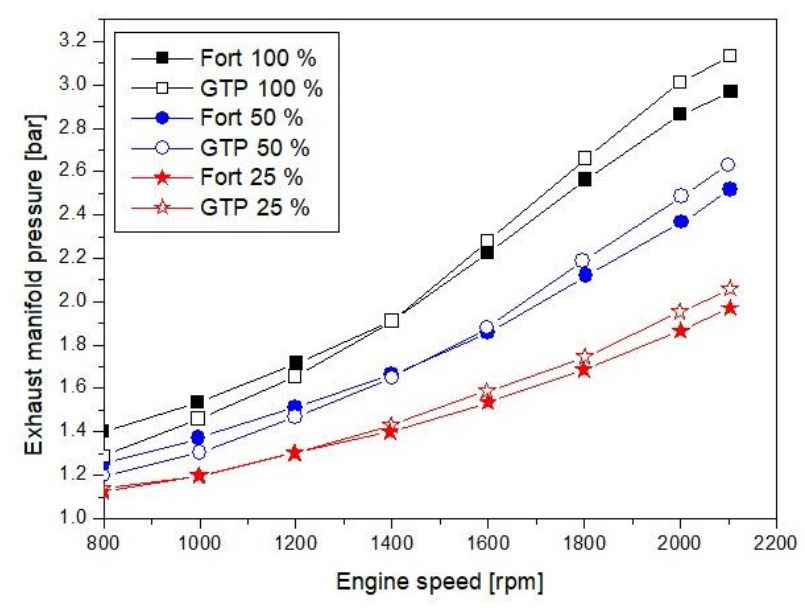

Fig. 7 Exhaust manifold pressure

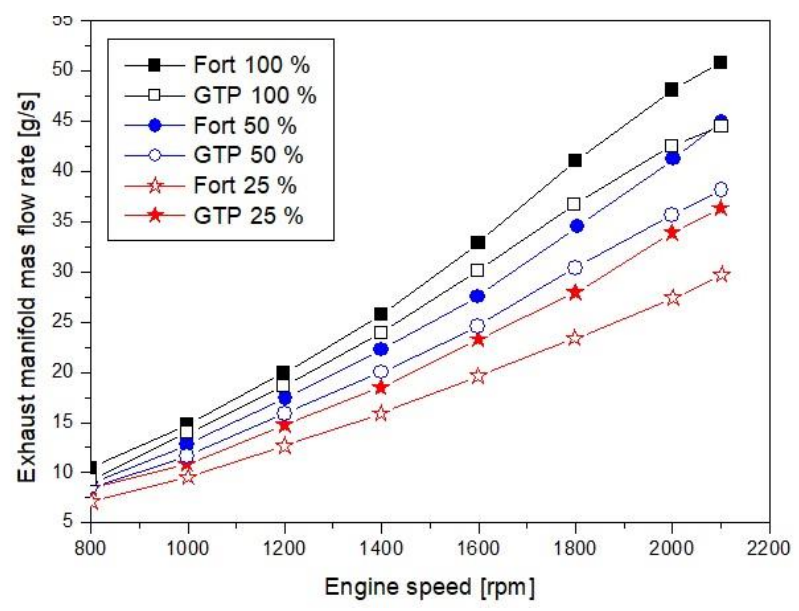

Fig. 9 Exhaust manifold mass flow rate

pressure and also the intake valve opens before (TDC) causing a compression wave to propagate towards the valve and results in a pressure rise at that point. After piston movement changes direction, a depression will promptly develop in the cylinder.

Figs. 12 and 13 show the instantaneous temperature through the inlet and the exhaust valves with respect to crank angle, for different engine speeds. It has a similar trend as the pressure since temperature is pressure dependent.

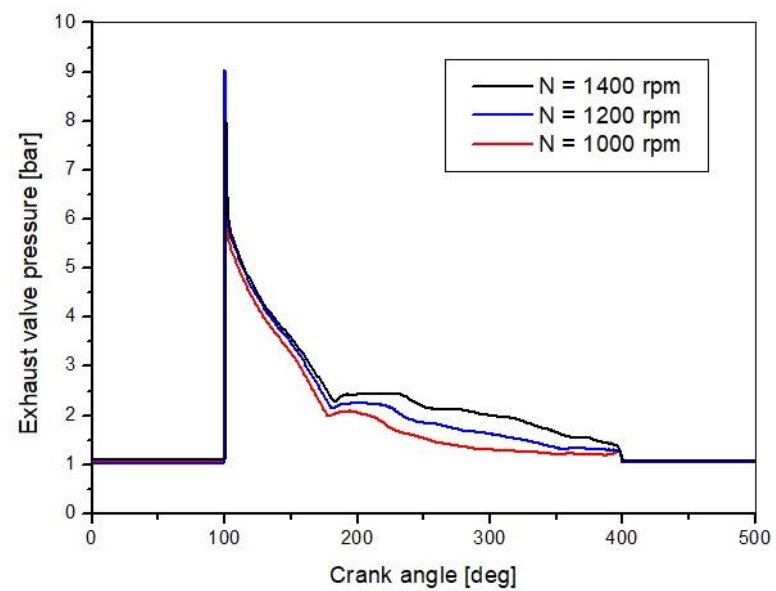

Fig. 11 Pressure variations in the exhaust valve during gas exchange period 


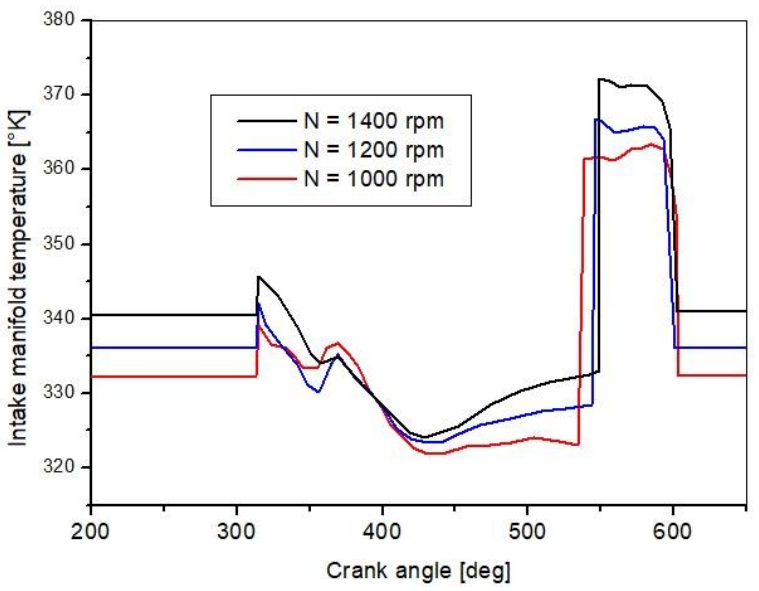

Fig. 12 Temperature variations in the intake valve during gas exchange period

The mass flow rate performance of the intake valve and exhaust valve showed in Figs. 14 and 15. For the both valves the mass flow rate increase with the engine speed. In figure 14 the engine models the exhaust valve open start from 100 on crank angle degree and close in 400 on crank

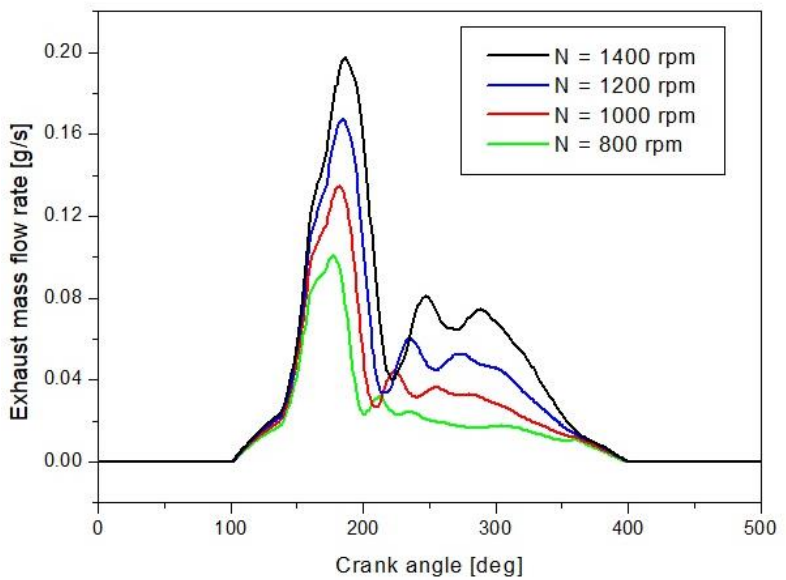

Fig. 14 Mass flow rate in exhaust valve

\subsection{Cylinder parameters}

Fig. 16 show the cylinder mass of gases versus crank angle for different engine speed; 1100, 1200, 1300 and $1400 \mathrm{rpm}$, the cylinder mass increase with engine speed.

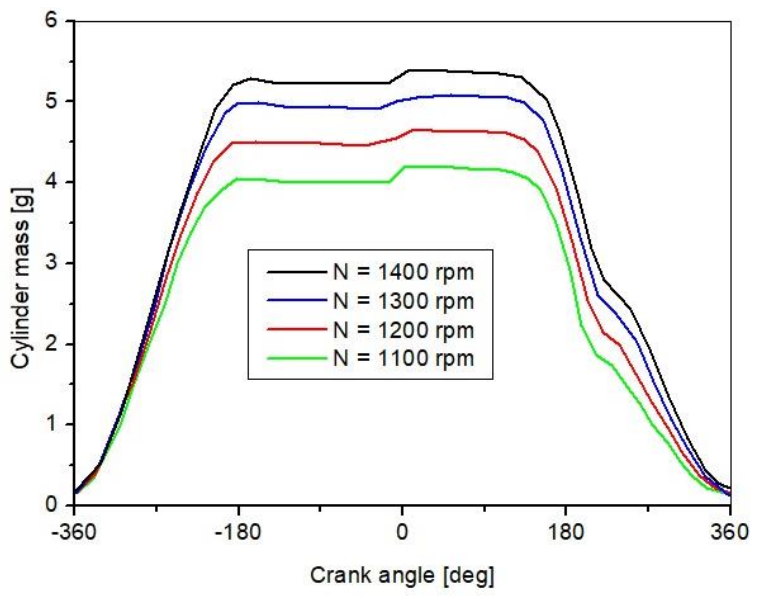

Fig. 16 Mass gases in the cylinder versus crank angle for different engine speed

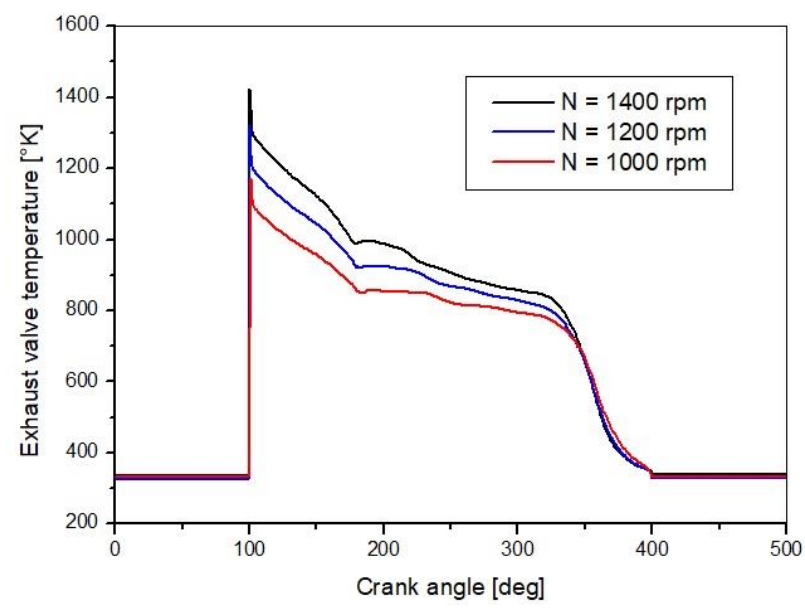

Fig. 13 Temperature variations in the exhaust valve during gas exchange period

angle degree. The maximum exhaust valve lift of the model is $12.286 \mathrm{~mm}$. in Fig. 15, the intake valve open start from 314 on crank angle degree and close in -118 on crank angle degree. The maximum intake valve lift of the model is the same with exhaust valve lift $11.103 \mathrm{~mm}$.

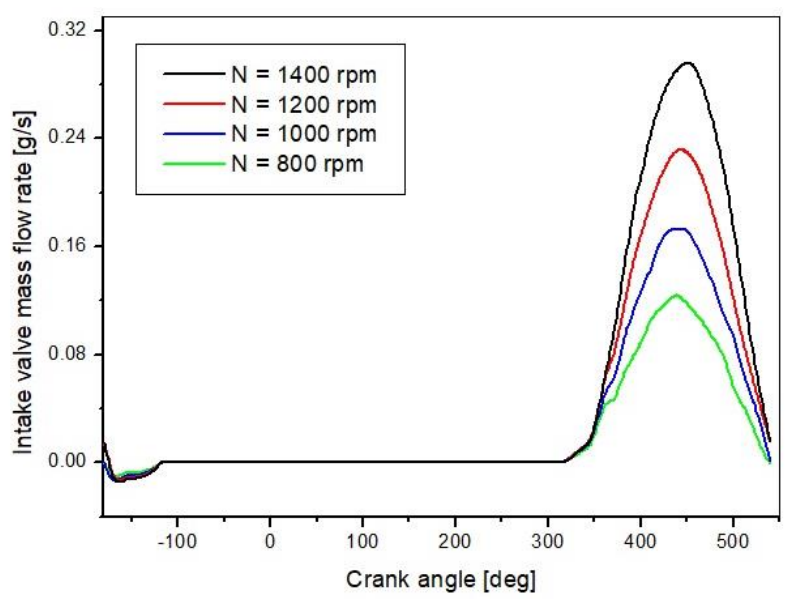

Fig. 15 Mass flow rate in intake valve

Figs. 17 and 18 shows the pressure and the temperature variations in the cylinder with respect to crank angle during the gas exchange period for different engine speeds. The cylinder calculations were carried out for complete open period, from the exhaust valve open to the intake valve close (EVO to IVC). Fig. 17 reveals that a significant difference in the timing of the wave is observed as engine speed changes. However, it is noticed that the transient pressure is sharply reduced during EVO in the blow down period and before IVO the wave pattern is basically made up of pressure pulses; these pulses combine to give a single pulse as engine speed increases, this is because the number of pulses for a given engine is a function of piston movement (piston position), valve opening and engine speed. The pressure at IVO is generally higher than the atmospheric pressure and its value is a function of engine speed, this is because the intake valve is opened before (TDC). By the time the exhaust valve closes, the pressure has dropped to a value less than atmospheric pressure, which is again a function of engine speed. The pressure increases again after reaching its minimum and appositive pressure in the cylinder gradually builds up. 
Fig. 18 show also the variation in the temperature in cylinder during the exhaust period. It is observed that the sequence of events for the temperature variation in the cylinder coincides with that of the pressure variations. It also shows that after EVO the released temperature decreases rapidly and because of the wave action, the temperature will be sustained or slightly raised until IVO, when fresh charge flows in and heat transfer takes place between the fresh charge and the residual gas. This will make the temperature in the cylinder decrease even more rapidly during the blow down period until after EVC, after this the temperature will gradually increase until IVC.

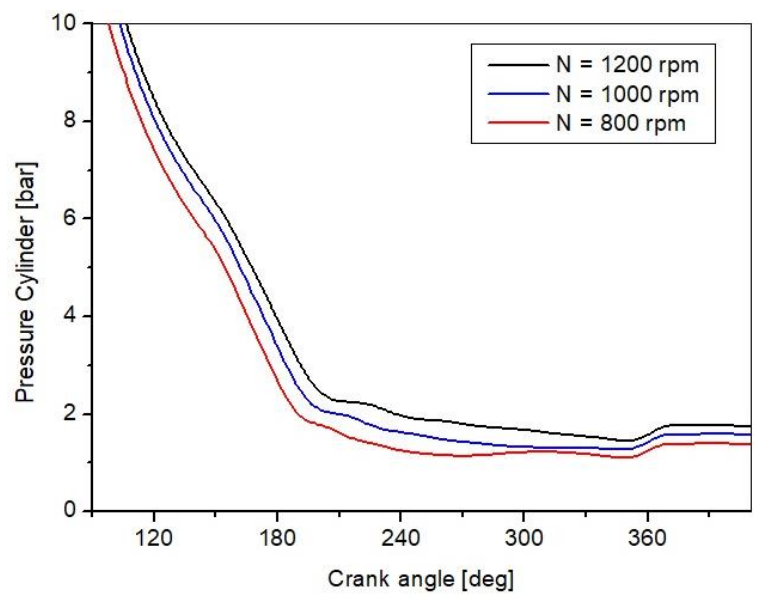

Fig. 17 Pressure variations inside the cylinder during gas xchange period at different speed

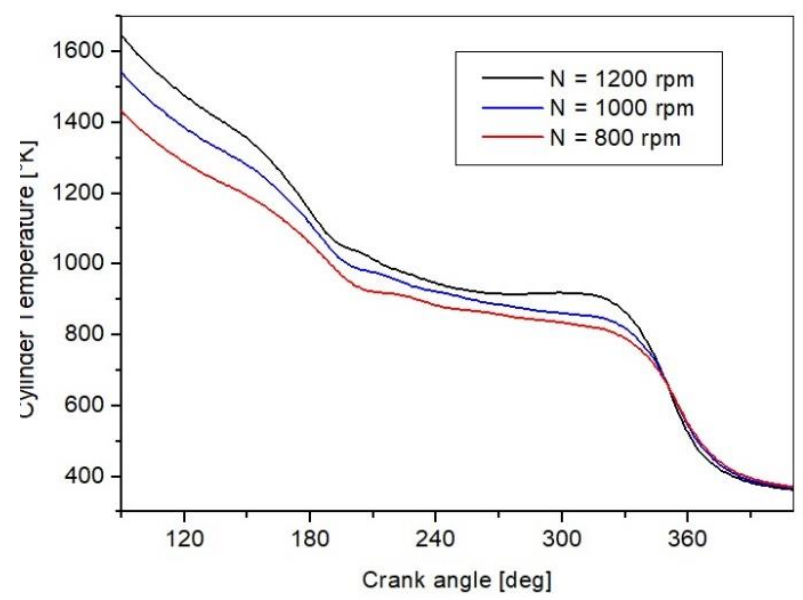

Fig. 18 Temperature variations inside the cylinder during gas exchange period at different speeds

\section{Conclusion}

The intake and exhaust valves temperature and pressure versus crank angle and engine speed can be used to obtain quantitative information to predict the characteristics of the intake and exhaust manifolds gas flow of the turbocharged diesel engine. The simulation results are shown that the highest intake and exhaust valves total pressure and temperature of the turbocharged diesel engine are in $1400 \mathrm{rpm}$. The mass flow rate, temperature and pressure of the intake manifold are increase with the increase of engine speed and mass fuel injected. The mass flow rate, and pressure of the exhaust manifold are increase with the increase of engine speed, but the temperature decrease. Based on this simula- tion it means that the turbocharged diesel engine can be increase the gas flow parameters in intake and exhaust manifolds if the engine speed and the mass fuel injected increases. The results the gas flow characteristics in the intake and the exhaust manifolds of the turbocharged diesel engine performance are compared for the tow software; FORTRAN and GT-POWER. There is a good concordance between results. For the future work, the effect of heat transfers in the intake and the exhaust manifolds would be interesting for the further investigation of the engine parameters. For making the model including heat transfer, the wall temperature of the intake and the exhaust manifolds has to be found by using a model for it. Also the accuracy of the heat transfer coefficient should be modeled.

\section{References}

1. Mariani, F.; Postrioti, L. 1996. Modelling diesel engine using KIVA II 3D-code: validation of a new global combustion model and its sensitivity to spatial discretization, SAE paper 960872.

https://doi.org/10.4271/960872.

2. Gandure, J.; Ketlogetswe, C. 2011. Comparative performance analysis of marula oil and petrodiesel fuels on a variable compression ratio engine, AFRICON, Victoria Falls, Livingstone: $13-15$.

http://dx.doi.org/10.4236/epe.2011.33042.

3. Watson, N.; Janota, M. S. 1982. Turbocharging the internal combustion engine, The Macmillan Press, New York.

https://catalogue.nla.gov.au/Record/403239.

4. Gamma Technologies. 2009. GT-Power User's Manual, GT-Suite Version 7.0. http://www.gtisoft.com/img/broch/broch_gtpower.pdf.

5. Guzzella, L.; Amstutz, A. 1998. Control of diesel engines, IEEE Transaction on Control Systems, 18: 53-71. http://dx.doi.org/10.1109/37.722253.

6. Ghoje, J.; Honnery, D. 2005. Heat release model for the combustion of diesel oil emulsions in DI diesel engine, Applied Thermal Engineering; 25: 2072-2085. https://doi.org/10.1016/j.applthermaleng.2005.01.016.

7. Zweiri, Y. H.; Whidborne, J. F.; Seneviratne, L. D. 1998. A mathematical transient model for the dynamics of a single-cylinder diesel engine, In Proceedings of the International Conference on Simulation, IEE, 30 September-2: 145-151.

http://dx.doi.org/10.1049/cp:19980629.

8. Depcik, C.; Assanis, D. 2002. A universal heat transfer correlation for intake and exhaust flows in an spark-ignition internal combustion engine, SAE Technical Paper Series, pp.2002-2003. http://dx.doi.org/10.4271/2002-01-0372.

9. Kaario, O.; Lendormy, E.; Sarjovaara, T.; Larmi, M.; Rantanen, P. 2007. In-cylinder flow field of a diesel engine, SAE Paper; No: 01-4046. http://dx.doi.org/10.4271/2007-01-4046.

10. Watson, N.; Marzouk, M. 1977. A non-linear digital simulation of turbocharged diesel engines under transient conditions, SAE Technical Paper, 770123. http://dx.doi.org/10.4271/800029.

11. Menacer, B.; Bouchetara, M. 2015. Computational thermodynamic of a turbocharged direct injection diesel engine, Mechanika 21(1): 40-50.

http://dx.doi.org/10.5755/j01.mech.21.1.8690. 
12. Hernandez, J. J.; et al. 2010. A combustion kinetic model for estimating diesel engine NOX emissions, Combustion Theory and Modelling 10(4): 639-657. http://dx.doi.org/10.1080/13647830600632758.

13. Heywood, J. B. 1988. Internal combustion engine fundamentals, McGraw-Hill, New York. http://dx.doi.org/10.1016/S0082-0784(75)80383-3.

14. Hohenberg, G. F. 1979. Advanced approaches for heat transfer calculations, SAE paper 1979-790825. http://dx.doi.org/10.1016/j.applthermaleng.2003.11.002.

15. Walke, N. H.; Nandgaonkar, M. R. 2016. NOx, soot, and fuel consumption predictions under transient operating cycle for common rail high power density diesel engines, Journal of Combustion, Article ID 1374768, 13 pages. http://dx.doi.org/10.1155/2016/1374768.

16. Rakopoulos, C. D.; Dimaratos, A. M. 2011. Investigation of turbocharged diesel engine operation, exhaust emissions, and combustion noise radiation during starting under cold, warm, and hot conditions, Proceedings of the Institution of Mechanical Engineers:1118-1133. https://doi.org/10.1177/0954407011400155.

17. Ashino, R.; Nagase, M.; Vaillancourt, R. 2000. Behind a beyond the Matlab ODE suite, Computers \& Mathematics with Applications 40(4): 491-512. https://doi.org/10.1016/S0898-1221(00)00175-9.
Brahim Menacer, Boussad Ait Slimane,

Mostefa Bouchetara

INVESTIGATION OF INTAKE AND EXHAUST

MANIFOLDS PARAMETERS OF A TURBOCHARGED

DIESEL ENGINE BASED ON STEADY-STATE SIMULATION

S u m m a r y

In the present work an approach to simulate and predict the flow characteristic in the intake and the exhaust manifolds of a six-cylinder four-stroke turbocharged diesel engine using GT-POWER and FORTRAN, for steady-state simulation. The simulation model covers the full engine cycle consisting of intake, compression, power and exhaust. The simulation and the prediction shown the diesel engine intake and exhaust manifolds parameters based on the crank angle degree. The results of the engine performances as well as pressure, temperature and mas flow rate in the intake and exhaust manifolds obtained by the developed program in language FORTRAN using the method of filling and emptying are presented. The commercial GT-Power software is used to the results validation. The range of variation of the rotational speed of the diesel engine chosen extends from $800 \mathrm{rpm}$ to $2100 \mathrm{rpm}$.

Keywords: Diesel engine performances, intake and exhaust manifolds, method of characteristic, filling and emptying method, quasi-steady method, computational simulation, turbocharger, thermodynamics.

Received November 01, 2018 Accepted April 25, 2019 